\title{
EL DERECHO A LA MOTIVACIÓN DE LAS RESOLUCIONES JUDICIALES EN LA JURISPRUDENCIA DEL TRIBUNAL CONSTITUCIONAL Y EL DERECHO A LA CLARIDAD: REFLEXIONES EN TORNO A UNA DESEADA MODERNIZACIÓN DEL LENGUAJE JURÍDICO ${ }^{1}$
}

\author{
Ciro Milione
}

doi: 10.18543/ed-63(2)-2015pp173-188

\begin{abstract}
SuMARio: 1. PREMisa. 2. LA MOTIVACIÓN DE LOS ACTOS JUdiciales: FUNCIÓN Y CONTENIDO CONSTITUCIONAL. 2.1. Derecho de prestación y acierto del Juez. 2.2. Razonabilidad, falta de arbitrariedad, lógica y error. 2.3. La extensión. 2.4. La congruencia. 3. DEL DERECHO A LA MOTIVACIÓN AL DERECHO A LA CLARIDAD. 3.1. La trascendencia del lenguaje jurídico y su deseada modernización. 3.2. ¿Existe un «derecho a la claridad de las resoluciones judiciales»? 4. CONCLUSIONES.
\end{abstract}

\section{PREMISA}

El 30 de diciembre de 2009 el Consejo de Ministros constituyó una Comisión de modernización del Lenguaje Jurídico. Dicha Comisión, presidida por el Secretario de Estado de Justicia e integrada por un vicepresidente y por

${ }^{1}$ Una primera versión de este estudio constituyó objeto de una comunicación al XI Congreso Extraordinario de la Asociación de Constitucionalistas de España (ACOES), celebrado en Barcelona los días 21 y 22 de febrero de 2013. Dicho estudio ha sido citado en las Sentencias n. ${ }^{\circ}$ 209/14 y n. ${ }^{\circ}$ 232/14 de la Corte Superior Sección Adolescentes de la República Bolivariana de Venezuela. 
ocho vocales procedentes de ámbitos distintos (jurídicos y lingüísticos), debía cumplir con el difícil cometido de formular una serie de recomendaciones sobre el lenguaje empleado por los profesionales del Derecho con un único fin: hacerlo «más claro y comprensible para los ciudadanos».

A distancia de seis años desde la formulación de una serie de propuestas importantes, es hoy posible afirmar que uno de los logros más destacados de esta Comisión fue el de plantear la existencia de un supuesto «derecho a la claridad», dotado de características singulares.

A través de la descripción de los elementos característicos del derecho a la motivación de los actos judiciales, este trabajo intentará dar respuesta a una pregunta cada vez más actual: ¿existe un derecho a la claridad en el lenguaje jurídico y, más concretamente, a la claridad de las resoluciones judiciales?

\section{LA MOTIVACIÓN DE LOS ACTOS JUDICIALES: FUNCIÓN Y CONTENIDO CONSTITUCIONAL}

La norma que consagra en nuestro ordenamiento jurídico el derecho a la tutela judicial efectiva es el Art. 24 de la Constitución de 1978 (a partir de aho$\mathrm{ra}, \mathrm{CE})^{2}$. No obstante, este precepto no hace ninguna explícita referencia al derecho a la motivación, nadie puede dudar de que esta prerrogativa constituya una vertiente del derecho consagrado en el citado Art. $24 \mathrm{CE}$. Esto es lo que expresa el mismo Tribunal Constitucional recordando en numerosas ocasiones $^{3}$ que «la obligación de motivar [...] forma parte del derecho fundamental de los litigantes a la tutela judicial efectiva, garantizado en el Art. 24.1 CE» ${ }^{4}$.

Sin embargo, pensar que la Constitución haga del todo caso omiso de esta exigencia de la Justicia sería equivocado. La obligación de motivar, en efecto, se encuentra formalmente proclamada en el Art. 122.3 CE según el cual «las sentencias serán siempre motivadas» ${ }^{5}$. La referencia a un tipo determi-

${ }^{2}$ Aunque -merece la pena recordarlo- otras normas convencionales completan el alcance de este importantísimo derecho fundamental. Entre todas, el Art. 6 del Convenio Europeo de Derechos Humanos y Libertades Públicas (CEDH), firmado en Roma en 1950. Sobre la trascendencia de este precepto, señalaría MiLione, C.: El Derecho a la tutela judicial efectiva en la jurisprudencia del Tribunal Europeo de Derechos Humanos, Tirant Lo Blanch, Valencia, 2015.

${ }^{3}$ Una entre todas, la sentencia del Tribunal Constitucional (a partir de ahora, STC) 36/2006, de 13 de febrero.

${ }^{4}$ Es oportuno evidenciar que el Tribunal Constitucional ha considerado siempre el derecho a obtener una resolución de fondo motivada en Derecho, como un elemento característico de la «tutela efectiva». Cfr. en particular la STC 24 de 14 de julio de 1981, en particular el FJ 3. .

5 Siendo la exigencia de motivar las sentencias una consecuencia y manifestación directa del principio de sumisión del juez a la ley, consagrado en el Art. 117.1 CE y en el 
nado de resoluciones judiciales - «las sentencias»- parece acotar en exceso ${ }^{6}$ el ámbito de aplicación de algo que podemos configurar como una obligación para los integrantes del Poder Judicial y, como un derecho para las partes procesales ${ }^{7}$.

Aun así, nadie considera que el derecho a la motivación queda limitado sólo a ese estrecho ámbito, pues sólo una lectura superficial del texto constitucional español podría llevarnos a esta conclusión.

En realidad, la necesidad de motivar todas las resoluciones judiciales, y no sólo las sentencias, responde a una exigencia que emana del principio de legitimación democrática del poder judicial y, además, en ella se sustancia la proscripción de la indefensión.

Así, no cabe duda de que la obligación de motivar las sentencias -o, más extensivamente, todas las resoluciones judiciales- responde a una exigencia íntimamente relacionada con los principios propios de un Estado de Derecho (Art. 1.1 CE) y particularmente con el carácter vinculante que para Jueces y Magistrados tiene la Ley, a cuyo imperio están sometidos en el ejercicio de su potestad jurisdiccional (Art. 117.1 y 117.3 CE).

En este sentido, la motivación sirve para demostrar que el fallo representa una decisión razonada en términos jurídicos y no un simple y arbitrario acto de voluntad de quien está llamado a juzgar.

La obligación de explicitar la lógica jurídica que subyace a una resolución judicial tiene además un alcance subjetivo. Forma parte del derecho fundamental de los litigantes a la tutela judicial efectiva, garantizado en el Art. 24.1 $\mathrm{CE}^{8}$, pues a través de la motivación, se hace posible la fiscalización de todo proceso de interpretación y aplicación del Derecho que los órganos jurisdiccionales llevan a cabo en el desarrollo de sus funciones constitucionalmente establecidas 9 .

Art. 1 de la Ley Orgánica 6/1985, de 1 de julio, del Poder Judicial, tal y como demostraremos más adelante.

${ }^{6}$ En efecto, otra formulación hubiera sido más oportuna, como por ejemplo la adoptada por el Art. 111.6 de la Constitución italiana, que, al hacer referencia a todas las resoluciones judiciales en general («Tutti i provvedimenti giurisdizionali devono essere motivati») puede considerarse más exhaustiva.

7 En este sentido, cabe recordar la STC 36/2006, de 13 de febrero, por la que la motivación de las sentencias es, a la vez, una obligación constitucional para los jueces y, al mismo tiempo, un derecho fundamental de quienes intervienen en el proceso.

${ }^{8}$ Cfr. STC 24/1990, de 15 de febrero, en particular, el Fundamento Jurídico (a partir de ahora, FJ) $4 .^{\circ}$.

${ }^{9}$ La STC 118/2006, de 24 de abril, (FJ 6. ${ }^{\circ}$ ) describe puntualmente todas las funciones desarrolladas por el derecho/obligación a la motivación. Particularmente interesante es la alusión que dicha sentencia realiza respecto al derecho de defensa. En efecto, el Tribunal Constitucional recuerda que el derecho a la motivación permite a los justiciables conocer 
La doctrina del Tribunal Constitucional pone en evidencia una serie de elementos que contribuyen a delinear la fisonomía del derecho a la motivación, es decir: la razonabilidad, la lógica, la congruencia, la falta de arbitrariedad, la extensión, la naturaleza de derecho de prestación, y por último, la inexistencia de un derecho al acierto. Todos factores constituyen, en definitiva, el verdadero contenido del derecho a obtener una resolución de fondo.

\subsection{Derecho de prestación y acierto del Juez}

El derecho a «obtener»-como la misma palabra indica- una resolución de fondo representa un derecho de prestación que recae en los órganos indicados por el Art. $117 \mathrm{CE}$ a favor de los justiciables.

La STC 243/2006, de 24 de julio, (FJ 5. $\left.{ }^{\circ}\right)^{10}$ indica que una resolución de fondo constituye una contraprestación respecto al petitum de las partes procesales. Sin embargo, dicha contraprestación resultaría sólo en parte satisfecha si la resolución que emanara de un órgano judicial no estuviera acompañada por la motivación. En efectos, en esta parte se sustancia un elemento fundamental de la decisión judicial, como es la que atañe a los criterios interpretativos adoptados respecto a la Ley aplicable al caso concreto ${ }^{11}$.

Para mejor acotar el contenido del derecho a una resolución motivada es necesario alejar este principio de otras supuestas prerrogativas que nuestra Constitución no reconoce, ni puede reconocer: entre ellos, sin duda alguna, el derecho al acierto del juez.

En distintas ocasiones ${ }^{12}$ el Tribunal Constitucional ha negado la existencia de este principio, rechazando la idea de que el derecho al acierto pudiese con-

los criterios jurídicos en los que se fundamenta la decisión judicial, y, en definitiva, actúa como instrumento preventivo de la arbitrariedad en el ejercicio de la jurisdicción.

${ }^{10}$ Según la Corte «este Tribunal ha declarado repetidamente que para que quepa admitir, desde la perspectiva constitucional, que una resolución constituye la prestación de tutela judicial a que da derecho el Art. 24.1 CE es necesario que la misma responda a un verdadero razonamiento.»

${ }^{11}$ La respuesta judicial no tiene por qué limitarse a estimar o desestimar, parcialmente o en su totalidad, la demanda de los justiciables, pudiéndose dar el caso -frecuente en la práctica- en que la resolución establezca sencillamente la inadmisión de la demanda misma. Lo corrobora la STC 118/2006, de 24 de abril, (FJ 4. ${ }^{\circ}$ ), al afirmar que «el derecho a la tutela judicial efectiva, garantizado en el Art. 24.1 CE, comprende el derecho de los litigantes a obtener de los Jueces y Tribunales una resolución motivada y fundada en Derecho [...] que puede ser de inadmisión si concurre causa legal para ello y así se aprecia razonadamente por el órgano judicial.» En este mismo sentido, véanse, entre otras, las SsTC 63/1999, de 26 de abril, (FJ 2. ${ }^{\circ}$ ); 206/1999, de 8 de noviembre, (FJ 4..$^{\circ}$ ); 198/2000, de 24 de julio, (FJ 2. ${ }^{\circ}$ ); 116/2001, de 21 de mayo, (FJ 4..$^{\circ}$ ).

12 Véanse las SsTC 151/2001, de 2 de julio, (FJ 5..$^{\circ}$ ); 162/2001, de 5 de julio, (FJ 4..$^{\circ}$ ); 118/2006, de 24 de abril, (FJ 6. ${ }^{\circ}$ ); 248/2006, de 24 de julio, (FJ 3..$^{\circ}$ ). En particular, en las 
siderarse incluido en la reconstrucción dogmática del derecho a la motivación judicial. En efecto, los derechos y garantías previstos en el Art. $24 \mathrm{CE}$ no garantizan que la actuación o interpretación de los órganos jurisdiccionales resulte ser «correcta» en términos absolutos, ni que dichas garantías pueden asegurar la completa satisfacción de las pretensiones formuladas en sede procesal ${ }^{13}$.

Por todo ello, el supremo interprete de la Constitución recuerda (STC $118 / 2006$, de 24 de abril, FJ $4 .^{\circ}$ ) que el fin último del conjunto de garantías previsto por el Art. $24 \mathrm{CE}$ consiste esencialmente en hacer posible «que las pretensiones se desenvuelvan y conozcan en el proceso establecido al efecto» y que dicho proceso «finalice con una resolución fundada en Derecho, la cual podrá ser favorable o adversa a las pretensiones ejercitadas» ${ }^{14}$.

Sin embargo, es oportuno destacar que la negación de la existencia del derecho al acierto no significa dejar sin consecuencias las actuaciones erróneas de los órganos jurisdiccionales. Así, en la STC 248/2006, de 24 de julio, el Tribunal Constitucional indica como intolerable la violación de todo derecho fundamental que sea consecuencia de una equivoca selección, interpretación o aplicación de normas jurídicas por parte de los órganos de Justicia.

En definitiva -y aunque pueda parecer redundante-, hay que recordar que el derecho de acierto no existe porque no puede existir ${ }^{15}$, porque la falibilidad es una de las características más propia de la naturaleza humana y de estos particulares seres humanos que llamamos a ejercer la función jurisdiccional. Así, mientras que nuestros jueces sigan siendo de carne y huesos, el Legislador que estableciera o garantizara que los órganos judiciales aplicarán e interpretarán, siempre y en todo caso, las normas de una manera correcta, pecaría por falta de realismo o, lo que es peor, de honestidad.

\subsection{Razonabilidad, falta de arbitrariedad, lógica y error}

Un estudio pormenorizado de la doctrina del Tribunal Constitucional, pone en evidencia la existencia de otra vertiente relevante del derecho a una resolución motivada: la razonabilidad de la respuesta judicial.

SsTC 221/2006, de 3 de julio, (FJ 3..$^{\circ}$ y 243/2006, de 24 de julio, (FJ 5..$^{\circ}$ ), el Tribunal Constitucional no reconoce a la jurisdicción de amparo la función de enjuiciar el acierto o desacierto judicial en la selección, interpretación, aplicación de las disposiciones legales.

${ }_{13}$ En este mismo sentido, cabe recordar, por todas, las SsTC 107/1994, de 11 de abril, (FJ 2. ${ }^{\circ}$ ); y 139/2000, de 29 de mayo, (FJ 4..$^{\circ}$ ). Sobre la inexistencia del derecho al acierto del juez, señalaríamos particularmente PULIDO QUECEDO, M.: «De la negación del derecho al acierto del Juez... al error patente como motivo de amparo», en Repertorio Aranzadi del Tribunal Constitucional, . $^{\circ}$ 2, 2002, pp. 1279-1282.

14 Véase además la STC 50/1982, de 15 de julio, (FJ 3. ${ }^{\circ}$ ).

15 Lo deja muy claro la STC 221/2006, de 3 de julio, «el derecho a la tutela judicial efectiva del Art. 24.1 CE no comprende "un imposible derecho al acierto del Juzgador"》». 
Lo corroboran numerosas sentencias ${ }^{16}$, entre las que destacaríamos la STC 215/2006, de 3 de julio, (FJ 3..$^{\circ}$ ), en la que se afirma que «el Art. 24.1 CE comprende el derecho [...] a obtener de los Jueces y Tribunales una respuesta fundada en Derecho, esto es, motivada y razonable y no incursa en arbitrariedad, irrazonabilidad o error patente.»

El mismo Tribunal Constitucional se preocupa de separar el aspecto que atañe a la validez del razonamiento jurídico de otro ontológicamente ajeno que concierne a la reconstrucción de los elementos fácticos objeto de prueba en el proceso. Así, la verdad o falsedad de unos hechos que fundamentan una respuesta judicial pueden -en línea de principio y desde un punto de vista puramente lógico- no tener nada que ver con la genuinidad y coherencia del razonamiento jurídico llevado a cabo por los órganos jurisdiccionales ${ }^{17}$.

Así, para el Tribunal Constitucional, no pueden considerase razonadas, y por lo tanto motivadas, aquellas resoluciones judiciales que a primera vista, arrancan de premisas inexistentes; o son patentemente erróneas; o siguen un desarrollo argumental que incurre en quiebras lógicas tan relevantes que las conclusiones alcanzadas no se pueden considerar fundadas en ninguna de las razones aducidas.

En este sentido, argumentando en contrario, la razonabilidad consistiría en una coherencia lógica y argumental sufragada por bases de partida existentes y no afectadas por error patente ${ }^{18}$.

Cabe preguntarse qué tipo o clase de error pueda viciar una motivación y configurar una lesión del derecho a la tutela judicial efectiva.

La respuesta la ofrece el Tribunal Constitucional (STC 118/2006, de 24 de abril, FJ $3 .^{\circ}$ ) al recordar que una resolución judicial fundada en un razonamiento equivocado por no corresponderse con la realidad, vulnera el derecho a la tutela judicial efectiva. Según esta Corte, el «error» es una falsa representación de la realidad referida a la determinación o selección del material de hecho o de los presupuestos sobre el que se asienta una decisión judicial de la que derivan efectos negativos en la esfera del justiciable $^{19}$.

16 Véanse las SsTC 35/1999, de 22 de marzo, (FJ 4. ${ }^{\circ}$ ); 195/2004, de 15 de noviembre, (FJ 2. ${ }^{\circ}$ ); 104/2006, de 3 de abril, (FJ 7. ${ }^{\circ}$ ).

${ }^{17}$ Es cierto que la lógica en sí misma no se ocupa de las verdades materiales, sino de las relaciones formales que existen entre estas verdades.

18 Así las SsTC 214/1999, de 29 de noviembre, (FJ 4. ${ }^{\circ}$ ); 223/2001, de 5 de noviembre, (FJ 5. ${ }^{\circ}$ ); 194/2004, de 15 de noviembre, (FJ 2. ${ }^{\circ}$ ); 228/2005, de 12 de septiembre, (FJ 3..$^{\circ}$ ); 269/2005, de 24 de octubre, (FJ 2. ${ }^{\circ}$ ); 104/2006, de 3 de abril, (FJ 7. ${ }^{\circ}$ ).

${ }_{19}$ En este mismo sentido, recordamos entre otras las SsTC 245/2005, de 10 de octubre (FJ 4. $\left.{ }^{\circ}\right) ; 6 / 2006$, de 10 de enero, (FJ 4..$^{\circ}$ ). 
En su STC 192/2006, de 19 de junio, (FJ 3. ${ }^{\circ}$ ), el Tribunal Constitucional indica en el detalle cuáles son aquellos presupuestos cuya concurrencia supone una violación del derecho a la tutela judicial efectiva por error en la motivación $^{20}$

- En primer lugar, se requiere que el error determine la decisión adoptada, es decir, debe constituir el soporte único o básico de la resolución (ratio decidendi);

- en segundo lugar, es necesario que este error sea imputable exclusivamente al órgano judicial, es decir, que no sea imputable a la negligencia de la parte ${ }^{21}$;

- en tercer lugar, el error debe de ser patente y de carácter eminentemente fáctico;

- y finalmente, ha de producir efectos negativos en la esfera jurídica de la parte.

Por último, el Tribunal Constitucional pone particular énfasis en una característica ulterior del derecho a la motivación de las resoluciones judiciales: la falta de arbitrariedad. En este sentido, el supremo intérprete de la Constitución excluye la posibilidad de que un órgano judicial pueda adoptar decisiones en función de una voluntad meramente discrecional, por lo tanto, política, personal, y ajena al mandato jurídico.

Es evidente que dicha característica es propia no sólo de esta particular vertiente de la tutela judicial efectiva sino de toda la construcción dogmática que gira en torno a la idea de «proceso justo» ${ }^{22}$. Por lo tanto, la falta de arbitrariedad puede considerarse como la consecuencia obvia de un proceso celebrado en el pleno respeto de todos aquellos postulados consagrados en el mismo Art. 24 CE.

Desde un punto de vista puramente lógico, una motivación fundada en Derecho constituye la exacta negación de la arbitrariedad. Lo corrobora el Tribunal Constitucional contraponiendo la arbitrariedad con aquel vínculo infran-

${ }^{20}$ Se trata de una reconstrucción dogmática sentada, entre otras, en las SsTC 142/2005, de 6 de junio, (FJ 2..$^{\circ}$ y $3 .^{\circ}$ ); 290/2005, de 7 de noviembre, (FJ 3..$^{\circ}$ y $4 .^{\circ}$ ); 64/2006, de 27 de febrero, (FJ 3. ${ }^{\circ}$ y $4 .^{\circ}$ ).

${ }^{21}$ Cfr. Art. 44.1 b) de la Ley Orgánica 6/2007, de 24 de mayo, del Tribunal Constitucional.

${ }^{22}$ Cabe asimismo recordar, que la prohibición de la arbitrariedad de los poderes públicos representa un principio constitucional básico, consagrado en el Art. 9.3 CE, constituyendo una verdadera fuente del ordenamiento jurídico. Al respeto, señalaríamos particularmente GRANADO HiJelmo, I.: «La interdicción constitucional de la arbitrariedad de los poderes públicos», en Hinojosa Martínez, E. y GonZÁlez-Deleito Domínguez, N. (Coord.): Discrecionalidad administrativa y control judicial: I jornadas de estudio del gabinete jurídico de la Junta de Andalucía, 1996, pp. 123-190. 
queable constituido por el principio de sumisión del juez a la Ley (Art. 117.1 CE; Art. 1 de la Ley Orgánica 6/1985, de 1 de julio, del Poder Judicial).

Así lo evidencia, por ejemplo, en la STC 36/2006, de 13 de febrero, (FJ 2. ${ }^{\circ}$ ), al afirmar que «este Tribunal ha reiterado que el derecho a obtener una resolución fundada en Derecho, favorable o adversa, es garantía frente a la arbitrariedad e irrazonabilidad de los poderes públicos $\rangle^{23}$.

\subsection{La extensión}

Otra característica fundamental del derecho a la motivación de las resoluciones judiciales consiste en la síntesis de las argumentaciones que dicha motivación debe incluir ${ }^{24}$.

Según la doctrina del Tribunal Constitucional ${ }^{25}$ esta garantía, implícitamente consagrada por el Art. $24 \mathrm{CE}$, no exige que la resolución judicial toque necesariamente todos los aspectos tratados en el juicio, considerándose suficiente que la motivación exponga las razones que justifican la decisión adoptada a pesar de la parquedad o sobriedad del razonamiento jurídico.

${ }^{23}$ En este mismo sentido, véanse las SsTC 112/1996, de 24 de junio, (FJ 2. ${ }^{\circ}$ ); 87/2000, de 27 de marzo, (FJ 6. ${ }^{\circ}$ ); 196/2003, de 27 de octubre, (FJ 6. ${ }^{\circ}$ ); 58/1997, de 18 de marzo, (FJ 2. ${ }^{\circ}$ ); 25/2000, de 31 de enero, (FJ 2..$^{\circ}$ ); 42/2004, de 23 de marzo, (FJ 4. ${ }^{\circ}$ ); y en particular STC 314/2005, de 12 de diciembre, (FJ 4. ${ }^{\circ}$ ), en la que se reconoce a la motivación una función preventiva de la arbitrariedad en el ejercicio de la jurisdicción.

No obstante, es oportuno señalar que la prohibición de la arbitrariedad de los órganos jurisdiccionales, no niega a priori la posibilidad de que dichos órganos adopten todos los recursos a su disposición para ampliar la garantía de los derechos. Lo señala eficazmente BERnAl CANO, N.: («El razonamiento jurídico del juez y las formas articuladas de justicia constitucional desde una perspectiva comparativa», en Anuario iberoamericano de justicia constitucional, n. ${ }^{\circ}$ 17, 2003, p. 39) afirmando que "para lograr un activismo que asegure la garantía judicial y eficacia concreta de los derechos, es preciso que los jueces amplien con prudencia su capacidad creativa, aún cambiando los criterios tradicionales o la jurisprudencia de la Corte Constitucional. Es importante señalar que dicha autonomía no es sinónimo de arbitrariedad ni de exceso de poder. En efecto, la medida del poder creador del juez constitucional está en el derecho positivo, en la coherencia jurídica. El juez puede ir más allá de la ley escrita, siempre y cuando no vulnere con ello la Constitución y la finalidad sea el fortalecimiento de la protección individual».

${ }^{24}$ Según señala el Tribunal Constitucional (STC 14/1991, de 28 de enero, FJ 2. ${ }^{\circ}$ ) el derecho a obtener una resolución de fondo permite «exigir un razonamiento judicial exhaustivo y pormenorizado de todos los aspectos y perspectivas que las partes puedan tener de la cuestión que se decide» ya que «deben considerarse motivadas aquellas resoluciones judiciales que vengan apoyadas en razones que permitan conocer cuáles han sido los criterios jurídicos esenciales fundamentadores de la decisión».

${ }_{25}$ Sólo para citar algunas, recordamos las SsTC 150/1988, de 15 de julio, (FJ 3. ${ }^{\circ}$ ); 150/1993, de 3 de mayo, (FJ 3. ${ }^{\circ}$ ); 2/1997, de 13 de enero, (FJ 3. ${ }^{\circ}$ ); 139/2000, de 29 de mayo, (FJ 4. $\left.{ }^{\circ}\right)$. 
Así, en la STC 118/2006, de 24 de abril, (FJ 6. ${ }^{\circ}$ ), la Corte señala la imposibilidad de apreciar en términos absolutos y generales la suficiencia de una motivación, reenviando a un examen del caso concreto la existencia de este requisito.

Es significativa, en este sentido, la STC 218/2006, de 3 de julio, (FJ 5.a) en la que se señala la imposibilidad de estimar un recurso de amparo por supuesta violación del Art. $24 \mathrm{CE}$ cuando la extensión de la motivación, según el parecer de la parte recurrente, se considera insuficiente por el mero hecho de no referirse expresamente a todos los argumentos empleados en un precedente recurso. En efecto, el Tribunal Constitucional señala que no le corresponde «censurar cuantitativamente la interpretación o concentración del razonamiento», sino más bien la presencia de aquellos elementos que son suficientes a excluir un ejercicio arbitrario de la función jurisdiccional.

\subsection{La congruencia}

Como es sabido, un proceso judicial consiste en una demanda (petitum) que una parte dirige a la autoridad jurisdiccional a la luz de un fundamento jurídico que la sustenta (causa petendi). En este sentido, la causa petendi representa el derecho en fuerza del cual se reivindica el petitum, es decir, el bien jurídico objeto de la demanda.

La motivación de una resolución judicial consiste en una respuesta de la autoridad judicial al petitum, por lo que se hace evidente que entre el fallo judicial y las reivindicaciones formuladas por las partes en el proceso debe existir un nexo de congruencia ${ }^{26}$.

El Tribunal Constitucional ${ }^{27}$ distingue tres tipos distintos de incongruencia, es decir, de disconformidad entre respuesta judicial y petitum: incongruencia infra petitum (u omisiva, o ex siletio); incongruencia extra petitum (o por exceso); e incongruencia ultra petitum.

${ }^{26}$ Es lo que claramente evidencia el Tribunal Constitución con la STC 264/2005, de 24 de octubre, (FJ 2. ${ }^{\circ}$ ), al afirmar que «la congruencia viene referida, desde un punto de vista procesal, al deber de decidir por parte de los órganos judiciales resolviendo los $l i$ tigios que a su consideración se sometan, exigiendo que el órgano judicial ofrezca respuesta a las distintas pretensiones formuladas por las partes a lo largo del proceso, a todas ellas, pero sólo a ellas, evitando que se produzca un desajuste entre el fallo judicial y los términos en que las partes formularon sus pretensiones, concediendo más o menos o cosa distinta de lo pedido». En este mismo sentido es posible señalar también las SsTC 124/2000, de 16 de mayo, (FJ 3..$^{\circ}$ ); 114/2003, de 16 de junio, (FJ 3..$^{\circ}$ ); 174/2004, de 18 de octubre, $\left(\mathrm{FJ} 3 .^{\circ}\right)$.

${ }^{27}$ Cfr. entre otras las SsTC 222/1994, de 18 de julio, (FJ 2..$^{\circ}$ ) y la 110/2003, de 14 de junio, (FJ 2..$^{\circ}$ ). 
Según esta Corte, la incongruencia infra petitum se produce cuando el órgano judicial deja sin contestar alguna de las pretensiones formuladas por las partes que no es posible considerar ni superfluas ni redundantes ${ }^{28}$.

Para poder apreciar los casos de incongruencia infra petitum el Tribunal Constitucional ha ido indicando una serie de criterios que la STC 36/2006, de 13 de febrero, $\left(\mathrm{FJ}_{3} .^{\circ}\right.$ ), entre otras ${ }^{29}$, enumera. Según esta Corte:

- en primer lugar, es necesario llevar a cabo un estudio pormenorizado de las circunstancias que caracterizan cada caso concreto;

- en segundo lugar, es preciso distinguir entre lo que es el petitum y las que son meras alegaciones aportadas por las partes en apoyo a la demanda judicial, pues, según el Tribunal Constitucional, el derecho a recibir una respuesta detallada por el órgano jurisdiccional se manifiesta sólo respecto al primero de estos dos supuestos;

- en tercer lugar, para poder constatar un caso de incongruencia omisiva es necesario que no resulte posible deducir los motivos de la respuesta judicial ni tan siquiera por el conjunto de los razonamientos que sustentan la decisión. Asimismo, habrá de comprobarse que la pretensión manifestada por la parte y omitida por el órgano judicial fuera efectivamente llevada a juicio en momento procesal oportuno para ello;

- por último, debe comprobarse que la omisión concierna a cuestiones que, de haber sido consideradas en la decisión, hubieran podido determinar un fallo distinto al pronunciado.

Sin embargo, la denominada incongruencia por exceso o extra petitum, se produce cuando el órgano judicial concede algo no pedido o se pronuncia sobre una pretensión que no fue oportunamente deducida por los litigantes, por lo que se produce un desajuste o inadecuación entre el fallo o la parte dispositiva de la resolución judicial y los términos en que las partes formularon sus pretensiones ${ }^{30}$. En este sentido, según estima el Tribunal Constitucio-

${ }^{28}$ Siempre que no quepa interpretar razonablemente el silencio judicial como una desestimación tácita cuya motivación pueda inducirse del conjunto de los razonamientos contenidos.

${ }^{29}$ Cabe señalar las SsTC 206/1998, de 26 de octubre, (FJ 2. ${ }^{\circ}$ ); y 205/2001, de 15 de octubre, (FJ 2. ${ }^{\circ}$ ).

${ }^{30}$ Como, eficazmente, pone en evidencia el Tribunal Constitucional en la STC 40/2006, de 13 de febrero, (FJ 2. ${ }^{\circ}$ ), «el principio iura novit curia permite al Juez fundar el fallo en los preceptos legales o normas jurídicas que sean de pertinente aplicación al caso, aunque los litigantes no las hubieren invocado», mientras que el juzgador «sólo está vinculado por la esencia y sustancia de lo pedido y discutido en el pleito, no por la literalidad de las concretas pretensiones ejercitadas, tal y como hayan sido formuladas por los litigantes, de forma que no existirá incongruencia extra petitum cuando el Juez o Tribunal decida o se pronuncie sobre una de ellas que, aun cuando no fuera formal y expresa- 
nal, la incongruencia por exceso constituye una lesión del Art. 24 CE cuando el desajuste entre el fallo judicial y los términos en que las partes han formulado sus pretensiones supone una modificación sustancial del objeto procesal.

De esta manera, el órgano jurisdiccional, concediendo más de lo pedido (ultra petitum) o algo distinto de lo pedido (extra petitum), emite un fallo que es extraño a las respectivas pretensiones de las partes, por lo que, consecuentemente, la decisión judicial se pronuncia sobre temas o materias no debatidas oportunamente en el proceso.

\section{DEL DERECHO A LA MOTIVACIÓN AL DERECHO A LA CLARIDAD}

Como hemos podido apreciar, la doctrina del Tribunal Constitucional ha contribuido de forma determinante a la definición del alcance y contenido del derecho a la motivación ${ }^{31}$.

El análisis expuesto en los párrafos anteriores evidencia un dato incontrovertible, es decir, que el supremo intérprete de la Constitución no menciona ni alude, en la definición de los elementos esenciales de las motivaciones judiciales, a un aspecto que sin embargo, debería destacar por su propia naturaleza: la claridad del lenguaje jurídico en la exposición de los argumentos fundados en el Derecho.

En efecto, un examen de la jurisprudencia del Tribunal Constitucional sobre esta particular condición de las resoluciones judiciales deja frustrado todo intento de encontrar alguna referencia a un supuesto «deber a la claridad del lenguaje jurídico» del que investir a jueces y magistrados en el desarrollo de sus funciones.

Igualmente, no hay rastro de un correlativo «derecho a la claridad» (o «derecho a comprender») de las partes judiciales y de los ciudadanos en su conjunto.

mente ejercitada, estuviera implícita o fuera consecuencia inescindible o necesaria de los pedimentos articulados o de la cuestión principal debatida en el proceso.»

31 En esta labor, es igualmente importante la jurisprudencia del Tribunal Europeo de Derechos Humanos que influye en la interpretación adoptada por nuestra jurisdicción constitucional en materia de tutela judicial efectiva. En particular, por lo que atañe al derecho a la motivación en la doctrina del Tribunal de Estrasburgo, cabe señalar AGUDO ZAMORA M. J.: «La interpretación de los derechos y libertades constitucionales a través de los Tratados Internacionales: La técnica del artículo 10.2», en GonZALEZ RuS, J.J. (Coord.): Estudios penales y jurídicos: homenaje al Prof. Dr. Enrique Casas Barquero, 1996, p. 33-42; así como Milione Fugali, C.: «El derecho a obtener una resolución de fondo en la jurisprudencia del Tribunal Europeo de Derechos Humanos y del Tribunal Constitucional español», en PÉrez Tremps, P. (coord.): La Reforma del Tribunal Constitucional: actas del V Congreso de la Asociación de Constitucionalistas de España, 2007, pp. 761-792. 
En realidad, el único contexto en el que el Tribunal Constitucional hace referencia a la importancia del lenguaje jurídico en la motivación de las resoluciones judiciales se encuentra en la STC 108/2005, de 9 de mayo de 2005. En el fallo de dicha sentencia, la Corte admite la vulneración del Art. 24 CE (violación del derecho a la motivación) al reconocer «no fundada en derecho» una resolución en la que la determinación de la cuantía de una multa se llevaba a cabo «en virtud de un razonamiento por completo extraño a las mismas [es decir, a las pautas establecidas por el Código Penal] y más propio del lenguaje coloquial que del lenguaje jurídico que cabe reclamar de los órganos judiciales.»

Este conjunto de circunstancias - la asentada doctrina constitucional relativa al derecho a la motivación y, particularmente, la ausencia de referencias a la comprensibilidad del lenguaje a utilizar en las resoluciones judicialesparecen conducir a una conclusión: el lenguaje jurídico y su claridad no constituyen un derecho constitucionalmente relevante.

Aunque estas deducciones sean incontrovertibles desde la perspectiva de la jurisprudencia constitucional, otras circunstancias, sin embargo, nos conducen a unas conclusiones distintas por las que la claridad del lenguaje de las sentencias no sólo representa un verdadero valor jurídico, sino que además constituye un aspecto ulterior de la tutela judicial efectiva sobre el que parece concentrarse la atención del Legislador español en estos últimos años.

\subsection{La trascendencia del lenguaje jurídico y su deseada modernización}

La importancia del lenguaje jurídico radica en la importancia misma del Derecho como instrumento creado por el hombre con el fin de ordenar las relaciones humanas. Desde esta perspectiva, es suficiente pensar que dichas funciones son posibles sólo en la medida en que las normas que integran el ordenamiento jurídico sean consideradas necesarias, sean respetadas $\mathrm{y}$, antes que nada, conocidas por el conjunto social.

En este sentido, el lenguaje jurídico representa un vehículo a través del que los ciudadanos toman conocimiento del Derecho ${ }^{32}$, y esto en todas sus formas, es decir, no sólo cuando el Derecho adquiere el aspecto de normas elaboradas por los órganos constitucionales depositarios de la voluntad popular, sino también cuando asume las formas de resoluciones judiciales que aplican dichas normas al caso concreto ${ }^{33}$. En ambos casos y desde ambas

32 Iturralde Sesma, V.: Aplicación del derecho y justificación de la decisión judicial, Tirant lo Blanch, Valencia, 2003, p. 35, subraya «el carácter del Derecho dependiente del lenguaje», afirmando además que «el soporte lingüistico del Derecho es un hecho sine qua non de la existencia del mismo».

${ }^{33}$ Es significativo el arranque del artículo doctrinal de Olvera LóPEZ, J. J.: («El lenguaje de las sentencias y el derecho a la información», en Lex. Difusión y Análisis, 
perspectivas la calidad del lenguaje jurídico es, sin ninguna duda, decisiva como destaca unánimemente la doctrina científica ${ }^{34}$.

A lo largo de estos últimos años, la preocupación por la mejora y la modernización del lenguaje jurídico ha ido creciendo ${ }^{35}$, hasta lograr un espacio, cada vez más amplio en la agenda de los poderes públicos ${ }^{36}$.

Significativa, en este sentido, ha sido la elaboración del «Informe de la Comisión de Modernización del Lenguaje Jurídico» presentada en septiembre de 2011 y de las recomendaciones en el contenidas, dirigidas no sólo a los

N. ${ }^{\circ} 110$, agosto 2004, p. 54) en el que el autor, preguntándose «¿para quién escriben los jueces? » llega a la conclusión que «el destinatario final de toda sentencia es el público en general y, por ende, el lenguaje en ella utilizado debe ser ante todo claro, pues sólo de esa manera el juzgador hará posible el acceso real a esa garantía». Desde esta perspectiva, el mismo derecho a la publicidad procesal viene a corroborar esta tesis como yo mismo señalo en Milione FugALI, C.: «El derecho a un proceso público en la jurisprudencia del Tribunal Europeo de Derechos Humanos», en Anuario da Facultade de Dereito da Universidade da Coruña, N. ${ }^{\circ}$ 14, 2010, pp. 549-572.

${ }^{34}$ Así, sólo para citar algunos autores, cabe recordar PrIETO DE PEDRO, J. J.: («La exigencia de un buen lenguaje jurídico y Estado de Derecho», en Revista de administración pública, N. ${ }^{\circ} 140,1996$, p. 111) por el que «un buen Derecho no es posible sin un buen lenguaje [...] este aserto tiene mucho que ver con las mejores esencias, con las esencias más hondas, del Estado democrático, de Derecho y de Cultura»; o ROBLES MoRCHON, D.: (Comunicación, lenguaje y Derecho. Algunas ideas básicas de la teoría comunicacional del Derecho, Real Academia de Ciencias Morales y Políticas, Madrid, 2009, p. 26) según el cual «la realidad en la que el Derecho vive y se expresa es la propia de los fenómenos comunicativos. Bien es cierto que la comunicación [...] excede los límites de los ámbitos jurídicos y que, en este sentido no todo lo que es comunicación es Derecho. Ahora bien, la afirmación inversa sí es correcta: todo lo que es Derecho es comunicación.»

${ }^{35}$ Como demuestran, entre todos CAzorla Prieto, L. M.: (El lenguaje jurídico actual, Cizur Menor, 2007, p.88) «la arquitectura formal del lenguaje jurídico suele tender a la desmesura y al alargamiento superfluo y confundidor»; asimismo, cabe citar NAVA GOMAR, S. O.: («La sentencia como palabra e instrumento de la comunicación», en Revista Justicia Electoral, Vol. 1, N. ${ }^{\circ}$ 6, 2010, pp. 48-50) que enumera una serie de «aspectos negativos» del lenguaje jurídico actual, tales como su especialidad, su especialización, su carácter demiúrgico, arcano, sobrecargado y apelmazado, su «tendencia al idiotismo expresivo», su inmovilismo, su pluriformidad, o su inclinación al aislamiento.

36 Vd. GonzÁlez Salgado, J. A.: «El lenguaje jurídico del siglo XXI», en Diario La Ley, N. ${ }^{\text {7 } 7209,2009}$. En este contexto se enmarca, por ejemplo, la redacción de la Carta de Derechos del Ciudadano ante la Justicia, aprobada por unanimidad del Pleno del Congreso de los Diputados el día 16 de abril de 2002 (y particularmente, por lo que atañe a la motivación de las resoluciones judiciales, su Art. 7); la Orden JUS/3126/2003, de 30 de octubre, por la que se creó, en seno al Ministerio de Justicia, la Comisión para la Modernización del Lenguaje Jurídico; el Plan de Transparencia Judicial aprobado por Acuerdo del Consejo de Ministros de 21 de octubre de 2005; así como la firma en 2006 de un convenio de colaboración entre la Real Academia Española y la Vicepresidencia del Gobierno para la mejora de la redacción legislativa. 
profesionales del Derecho, sino también a las instituciones públicas e incluso a los medios de información. Igualmente significativa ha sido la firma, el 21 de diciembre de 2011, de un Convenio entre sujetos institucionales distintos ${ }^{37}$ llamados no sólo a impulsar la implementación de las recomendaciones recogidas en la Comisión de modernización del lenguaje jurídico ${ }^{38}$, sino también a renovar y perpetuar el trabajo de dicha asamblea.

\section{2. ¿Existe un «derecho a la claridad de las resoluciones judiciales»?}

El análisis de los instrumentos dirigidos a impulsar la promoción de la claridad en el lenguaje jurídico demuestra un dato incontrovertible: dichas iniciativas, en ningún caso, han ido más allá de la formulación de meras declaraciones de intenciones.

Aunque es innegable el valor de los informes de las distintas Comisiones de expertos en cuanto a sensibilización de juristas y profesionales del ámbito jurídico, ninguno de dichos instrumentos ha servido para que se afirmara la existencia de un «derecho a la claridad» del lenguaje jurídico -y del lenguaje jurídico en las resoluciones judiciales- positivo y real.

Esta conclusión sigue siendo pacífica aun cuando la palabra y el concepto de «derecho individual» viene empleada para enfatizar la importancia del lenguaje jurídico de las sentencias y de su claridad. Así, por ejemplo, aun siendo indudable que el Art. 7 de la «Carta de Derechos del Ciudadano ante la Justicia» proclame textualmente que «El ciudadano tiene derecho a que las sentencias y demás resoluciones judiciales se redacten de tal forma que sean comprensibles por sus destinatarios, empleando una sintaxis y estructura sencillas, sin perjuicio de su rigor técnico», lo que es necesario recordar es que, formalmente, la Carta ha sido aprobada -por unanimidad del Congreso de los Diputados, esto sí- con las formas propias de las «proposiciones no de Ley», con todo lo que ello conlleva de cara al valor normativo, a la eficacia jurídica y a la colocación en el sistema de fuentes del Derecho de estos peculiares instrumentos parlamentarios ${ }^{39}$.

${ }^{37}$ Más concretamente, la Real Academia Española, el Ministerio de Justicia, la Fiscalía General del Estado, la Real Academia de Jurisprudencia y Legislación, el Consejo General de la Abogacía Española, el Consejo General de Procuradores de España, la Conferencia de Decanos y Decanas de las Facultades de Derecho de España.

38 A través de «la formación lingüística de los profesionales del Derecho, el reconocimiento público de buenas prácticas, el acercamiento del lenguaje jurídico a la ciudadanía, la estandarización de documentos jurídicos, las tecnologías al servicio de la claridad del lenguaje, así como cualesquiera otras medidas en este ámbito», como señala la clausula primera del Convenio mismo.

39 Sobre la naturaleza de las proposiciones no de Ley, señalar MuÑOz ArNAU, J. A.: («Las proposiciones no de Ley», en Anuario jurídico de La Rioja, N. ㅇ 3, 1997, pp. 387- 
Consideraciones parecidas se pueden llevar a cabo respecto al Plan de Transparencia Judicial en el que existen referencias a la importancia de la claridad del lenguaje jurídico -incluso en las resoluciones judiciales- ${ }^{40}$; o a las recomendaciones de la Comisión de modernización del lenguaje jurídico que manifiestamente hablan de un «derecho a comprender» aun hallándose recogidas en un documento - un informe científico- que, formalmente, no constituye un instrumento legislativo concreto.

\section{CONCLUSIONES}

Este trabajo comenzó a partir de una pregunta concreta que se refería a la posible existencia de un supuesto derecho a la claridad de las resoluciones judiciales.

La respuesta a esta pregunta resulta evidente: un derecho con estas características no ha sido positivizado en el ordenamiento jurídico actual, si bien resulta evidente la existencia de un «deseo» de hacer del lenguaje de las sentencias y de las leyes un instrumento más accesible para toda la sociedad.

En un contexto político y social muy delicado, como es el en el que nos ha tocado vivir, la distancia entre ciudadanos y poderes públicos crece por numerosas razones, siendo una de ellas la incapacidad de estos últimos de comunicar con los ciudadanos, para sacrificar en el altar del oportunismo partidista, valores como la claridad y la transparencia.

GeORge Orwell afirmaba que «el lenguaje político está diseñado para que las mentiras parezcan verdades, el asesinato una acción respetable y para dar al viento apariencia de solidez» ${ }^{41}$. Estas consideraciones dolorosas no pueden, sin embargo, concernir al lenguaje jurídico que, por la misma

482) que «estas son mociones distintas de las de censura o confianza y su finalidad se agota en promover una deliberación del Congreso sobre un tema determinado» (p. 421) para luego matizar que «son instrumentos para introducir una deliberación sin más efectos ante la opinión pública» (p. 424).

${ }^{40}$ Referencias que, por cierto, no exceden la mera formulación de deseos y aspiraciones como eficazmente indica la letra del punto n. ${ }^{\circ} 7$, del Apartado IV, «Instrumentos del Plan de Transparencia judicial», por la que «convendrá conciliar criterios tendentes a desechar fórmulas y expresiones anacrónicas o vacías de contenido que no proporcionan ninguna información y, especialmente, prestar atención a la comprensibilidad de las citaciones que las Oficinas judiciales dirijan a los ciudadanos, quienes [...] todavía manifiestan, en un porcentaje que sería deseable reducir que no han entendido el lenguaje jurídico que los tribunales han empleado, permaneciendo como usuarios con más problemas con este lenguaje los de clase baja o media-baja, los usuarios de juicios de faltas y juicios penales y, más en concreto, los denunciados, los acusados, los testigos y los testigos-víctimas».

${ }^{41}$ Orwell, G.: Politics and the English Language, Horizont, abril 1946. 
razón de ser instrumento entregado a la ciencia del Derecho, debería ser ejemplo de coherencia y precisión.

Estas perspectivas conducen a reflexiones importantes sobre la verdadera naturaleza del Poder Judicial y sobre la función jurisdiccional que constituye un servicio público primordial en la construcción de un verdadero Estado de Derecho. Un poder público con estas características debe asegurar, respecto a sus ciudadanos, unos estándares de calidad elevados que sólo el cumplimiento de los principios de la tutela judicial efectiva puede garantizar.

TITTLE: The right to motivation of judicial resolutions in jurisprudence of Constitutional Court and the right to the clarity: reflections around a desired modernization of the juridical language

RESUMEN: El derecho a la tutela judicial efectiva y el mismo concepto de poder judicial como poder democrático postulan la existencia del derecho a la motivación de los actos judiciales. Sin embargo, jes posible afirmar que un aspecto de esta garantía procesal incluye también el derecho a la claridad de las resoluciones judiciales? Este artículo vierte sobre esta pregunta.

PALABRAS ClAVE: Derecho, motivación, claridad, constitucional, lenguaje.

ABSTRACT: The right to a fair process and the idea of the Judiciary as a democratic power itself suppose the existence of the right to a properly motivated ruling. Nevertheless, is it possible to defend that a facet of that right includes the right to the clarity of judicial decisions? This paper deals with these issues.

KEYWORDS: Right, decision, clarity, constitutional, language. 